\title{
Erratum to: Community-Partnered Cluster-Randomized Comparative Effectiveness Trial of Community Engagement and Planning or Resources for Services to Address Depression Disparities
}

\author{
Kenneth B. Wells, $M D, M P H^{1,2,3,4}$, Loretta Jones, $M A^{5,6}$, Bowen Chung, $M D^{1,2,7}$, \\ Elizabeth L. Dixon, RN, $P h D^{8}$, Lingqi Tang, $P h D^{2,4}$, Jim Gilmore, MBA 9 , Cathy Sherbourne, $P h D^{7}$, \\ Victoria K. Ngo, $\mathrm{PhD}^{7}$, Michael K. Ong, MD ${ }^{10}$, Susan Stockdale, PhD ${ }^{2,12}$, Esmeralda Ramos, $B A^{2}$, \\ Thomas R. Belin, $P h D^{2,17}$, and Jeanne Miranda, $P h D^{2,4}$ \\ 'RAND Corporation, Santa Monica, CA, USA; ${ }^{2}$ David Geffen School of Medicine, Departments of Psychiatry and Biobehavioral Sciences, \\ UCLA, Los Angeles, CA, USA; ${ }^{3}$ Department of Healthy Policy and Management, UCLA Jonathan and Karin Fielding School of Public Health, \\ Los Angeles, CA, USA; ${ }^{4}$ Center for Health Services and Society, UCLA Jane and Terry Semel Institute for Neuroscience and Human Behavior, \\ Los Angeles, CA, USA; ${ }^{5}$ Healthy African American Families II, Los Angeles, CA, USA; ${ }^{6}$ Charles R. Drew University of Medicine and Science, Los \\ Angeles, CA, USA; ${ }^{7}$ Harbor-UCLA Medical Center, Torrance, CA, USA; ${ }^{8}$ QueensCare Health and Faith Partnership, Los Angeles, CA, USA; \\ ${ }^{9}$ Behavioral Health Services, Gardena, CA, USA; ${ }^{10}$ Department of Medicine, David Geffen School of Medicine, UCLA Division of General \\ Internal Medicine and Health Services Research, Los Angeles, CA, USA; "1 UCLA Johnathan and Karin Fielding School of Public Health, \\ Department of Biostatistics, Los Angeles, CA, USA; ${ }^{12}$ Greater Los Angeles Veteran's Affairs, Los Angeles, CA, USA.
}

J Gen Intern Med 28(11):1534

DOI: $10.1007 / \mathrm{s} 11606-013-2501-6$

(c) Society of General Internal Medicine 2013

Erratum to: J Gen Intern Med

DOI: $10.1007 / \mathrm{s} 11606-013-2484-3$

In the original publication, one of the authors' funding sources was not acknowledged. The complete Acknowledgements are as follows:

Community Partners in Care was funded by Award Numbers R01MH078853, P30MH082760, and P30MH068639 from the National Institute of Mental Health and 64244 from the Robert Wood Johnson Foundation. The content is the responsibility of the authors and does not necessarily represent the views of the funders.

Corresponding Author: Kenneth B. Wells, MD, MPH; Center for Health Services and Society, UCLA Jane and Terry Semel Institute for Neuroscience and Human Behavior, Los Angeles, CA, USA (e-mail: kwells@mednet.ucla.edu).

The online version of the original article can be found at http:// dx.doi.org/10.1007/s11606-013-2484-3.

Published online May 24, 2013 